\title{
Performance Testing of a Photocatalytic Oxidation Module for Spacecraft Cabin Atmosphere Revitalization
}

\author{
Jay L. Perry ${ }^{1}$ Morgan B. Abney ${ }^{2}$, Kenneth R. Frederick ${ }^{3}$, and Joseph P. Scott ${ }^{4}$ \\ NASA Marshall Space Flight Center, Huntsville, Alabama, 35812, USA \\ and \\ Mark Kaiser ${ }^{5}$, Gary Seminara ${ }^{6}$, Alex Bershitsky ${ }^{7}$ \\ Honeywell International, Des Plaines, Illinois, 60017, USA
}

\begin{abstract}
Photocatalytic oxidation (PCO) is a candidate process technology for use in high volumetric flow rate trace contaminant control applications in sealed environments. The targeted application for PCO as applied to crewed spacecraft life support system architectures is summarized. Technical challenges characteristic of PCO are considered. Performance testing of a breadboard PCO reactor design for mineralizing polar organic compounds in a spacecraft cabin atmosphere is described. Test results are analyzed and compared to results reported in the literature for comparable PCO reactor designs.
\end{abstract}

\section{Nomenclature}

$C \quad=$ Celsius

$\mathrm{cm} \quad=$ centimeter

$f t \quad=$ feet

hr $\quad=$ hour

$m \quad$ = meter

$m g \quad=$ milligram

ppb $\quad=$ parts per billion by volume

ppm $\quad=$ parts per million by volume

\section{Introduction}

P PACECRAFT and space habitat environmental control and life support (ECLS) systems provide specific atmos$\checkmark$ phere revitalization (AR) functions to ensure high quality air for the crew. These functions include carbon dioxide $\left(\mathrm{CO}_{2}\right)$ removal, oxygen $\left(\mathrm{O}_{2}\right)$ supply and/or generation, humidity control, fire detection and suppression, and trace contaminant control (TCC). While all of these functions are essential, TCC is of particular interest because, while generation sources can be minimized, they can never be completely eliminated.

Two aspects of TCC are of particular concern as space exploration mission objectives extend beyond the Earthmoon system requiring the ECLS system to recycle critical resources. First is the potential unpredictability of contaminant generation rate spikes. Unexpected contamination spikes may result from system or payload leaks and spills as well as various housekeeping and personal hygiene activities carried out by the crew. Cabin contamination can also result from volatile contaminant intrusion into the cabin during extravehicular activity (EVA). The TCC equipment must be capable of broad spectrum control as well as possess sufficient operational margin to accommodate transient contamination events. Second, an ECLS system designed to maximize efficient recovery of resources

\footnotetext{
${ }^{1}$ Engineer, Environmental Control Systems, NASA Marshall Space Flight Center, Huntsville, AL 35812.

${ }^{2}$ Engineer, Environmental Control Systems, NASA Marshall Space Flight Center, Huntsville, AL 35812.

${ }^{3}$ Electronics Engineer, NASA Marshall Space Flight Center, Huntsville AL 35812.

${ }^{4}$ Chemist, ICRC/Jacobs/ESTS, NASA Marshall Space Flight Center, Huntsville, AL 35812.

${ }^{5}$ Principal Scientist, Honeywell, Advanced Technology, 50 East Algonquin Road, Des Plaines, IL 60017.

${ }^{6}$ Engineer I, Honeywell, Advanced Technology, 50 East Algonquin Road, Des Plaines, IL 60017.

${ }^{7}$ Principal Scientist, Honeywell, Advanced Technology, 50 East Algonquin Road, Des Plaines, IL 60017.
} 
must recycle water. Efficiently recovering and purifying water is central to a successful "closed loop" ECLS system. Trace contaminants in the cabin atmosphere inevitably impact water processing system functionality. Reducing the trace contaminant load presented to water processing equipment can be accomplished by strategically placing cabin trace contaminant control equipment upstream of the humidity control equipment. These considerations are central to a broad spectrum, operationally robust spacecraft cabin TCC equipment design and operational strategy.

Traditionally, the TCC equipment aboard crewed spacecraft are designed to address the volatile trace organic and inorganic chemical loads presented by equipment offgassing and human metabolism. ${ }^{1}$ TCC systems must provide cabin air quality that complies with spacecraft maximum allowable concentration (SMAC) standards defined by the National Aeronautics and Space Administration (NASA). ${ }^{2}$ Typically, the TCC process operating conditions and flow rates are driven by no more than five chemical compounds. Process flow rates are low, usually ranging between $15 \mathrm{~m}^{3} /$ hour and $25 \mathrm{~m}^{3} /$ hour. Operational margin is incorporated in the TCC equipment design to accommodate reasonably-sized spikes in contaminant generation rates. The TCC equipment usually processes the cabin air in parallel with other ECLS equipment, in particular the water recovery and purification systems. In such a configuration, the TCC equipment is unable to minimize trace contaminant mass transfer into humidity condensate. Future systems must be optimized for and integrated within the ECLS system architecture for this purpose.

In addition to AR functions, water processing systems are also essential to a closed loop ECLS system for long duration manned space flight. As in the natural world, air and water systems on board spacecraft inevitably interact, particularly through humidity condensate. Volatile polar organic compounds (VPOCs) in the air can be collected in humidity condensate and introduced to the water processing system. These VPOCs must then be removed by the water processing system to provide potable water to the crew. While expected levels of VPOCs are anticipated and easily handled by existing state-of-the-art (SOA) water processing systems, unexpected spikes can result in water that does not comply with potable standards. ${ }^{3}$ Because VPOCs are more easily removed from the gas phase as compared to the liquid phase, their removal by a TCC located upstream of the humidity condenser can reduce the size, weight, and complexity of future water processing systems. For future space vehicles, water processing engineers have specified an $80 \%$ single pass removal of polar VPOCs before the process air enters the humidity condenser.

The technical challenge presented by minimizing VPOC mass transfer into the humidity condensate requires a solution that provides high single pass removal efficiency and low power consumption while accommodating high volumetric flows in the range of $170 \mathrm{~m}^{3} / \mathrm{hr}$ to $680 \mathrm{~m}^{3} / \mathrm{hr}$. Traditional physical adsorption- and thermal catalytic oxidation-based process technologies provide the necessary removal efficiency performance but suffer from high power consumption and size issues when scaled to accommodate the required high volumetric flow conditions.

An alternative to SOA TCC system technologies has been proposed by Honeywell, Inc. to address the technical challenge presented by VPOCs. The system uses photocatalytic oxidation (PCO) to remove targeted VPOCs as well as other volatile contaminants at high volumetric flow conditions. NASA and Honeywell, Inc. initiated a joint development project in July 2008 that culminated in testing a breadboard-fidelity PCO unit from January through May 2010. The following summarizes the developmental work and key performance testing results.

\section{Background}

A photocatalyst is a material capable of forming electron-hole pairs when exposed to light to produce hydroxyl radicals $(* \mathrm{OH})$. In PCO, as shown in Fig. 1, the catalyst is illuminated while exposed to contaminants. Ideally, the contaminants are fully oxidized to form $\mathrm{CO}_{2}$ and water. However, partial oxidation of VPOCs such as ethanol can result in forming intermediate products such as acetaldehyde and acetic acid.

In terrestrial air systems, small quantities of these intermediates are not usually cause for concern due to the diluting effect provided by frequent exchange of external air with circulating air. However, for a confined space such as a spacecraft cabin, build-up of these intermediates can impact cabin air quality. Thus, in order for PCO technology to be a competitive option for SOA TCC systems, partial oxidation products must be minimized or eliminated.

The goals of the PCO development effort undertaken by Honeywell, Inc. included high ethanol mineralization combined with minimal production of

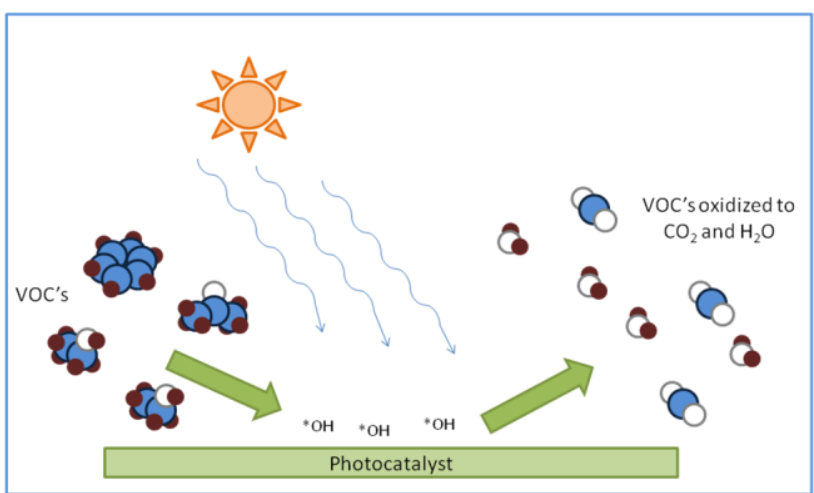

Figure 1. Photocatalytic oxidation uses light to create hydroxyl radicals. Organic compounds are oxidized by the radicals to form $\mathrm{CO}_{2}$ and water. 
partial oxidation products. The development work began in 2008 and a breadboard PCO unit, shown in Fig. 2, was fabricated and delivered in December 2009 to NASA's Marshall Space Flight Center (MSFC) for testing. This unit utilized a doped titania $\left(\mathrm{TiO}_{2}\right)$ catalyst applied to a metallic mesh screen substrate. Two mesh screens were combined to form a panel. The $64 \mathrm{~cm} \times 51 \mathrm{~cm} \times 36 \mathrm{~cm}$ unit contained a total of six panels. Ultraviolet (UV) lamps were placed between the panels.

\section{A. Test Setup and Conditions}

NASA testing of Honeywell's breadboard PCO unit was conducted in the Regenerative Environmental Control and Life Support (ECLS) Module Simulator (REMS), shown in Fig. 3, located in the North high-bay of Building 4755 at MSFC. The REMS provides a $\sim 201 \mathrm{~m}^{3}$ closed environment for hardware testing. Human metabolic and trace contaminant offgassing loads may be either simulated or supplied by test volunteers depending on the nature of the test.

The breadboard PCO unit was installed in the REMS working volume at approximately midchamber. A duct transition attached the PCO unit to a calibrated venturi flow meter, located downstream of the PCO unit. A variable speed fan pulled the atmosphere from the REMS working volume through the PCO unit and venturi flow meter. The exhaust from the PCO unit was directed into the REMS ventilation system supply inlet using a flexible duct.

Sampling ports were located directly upstream of the PCO unit (port 5) and downstream of the unit (port 6). This allowed test engineers to determine the performance of the PCO unit by observing inlet and outlet trace contaminant concentrations. Conditions within the REMS were maintained at relative humidity levels $30-60 \%, \mathrm{O}_{2}$ levels $19-22.5 \%$, and temperatures $20-25^{\circ} \mathrm{C}$. Samples taken from the circulating air through ports 5 and 6 were analyzed continuously using an MKS Multigas ${ }^{\mathrm{TM}} 2030$ Fourier-Transform Infrared (FTIR) system. The FTIR instrument method was tuned to target ethanol as its primary analyte. Periodically, gas chromatograph (GC) analysis was completed using an Agilent $5890 \mathrm{~N}$ gas chromatograph (GC) equipped with a flame ionization detector (FID). A Markes TT24/7 autosampler conditioned samples before introducing them into the GC. The GC analyses targeted all chemical molecules used to challenge the PCO unit including acetaldehyde.

\section{B. Test Conduct Summary}

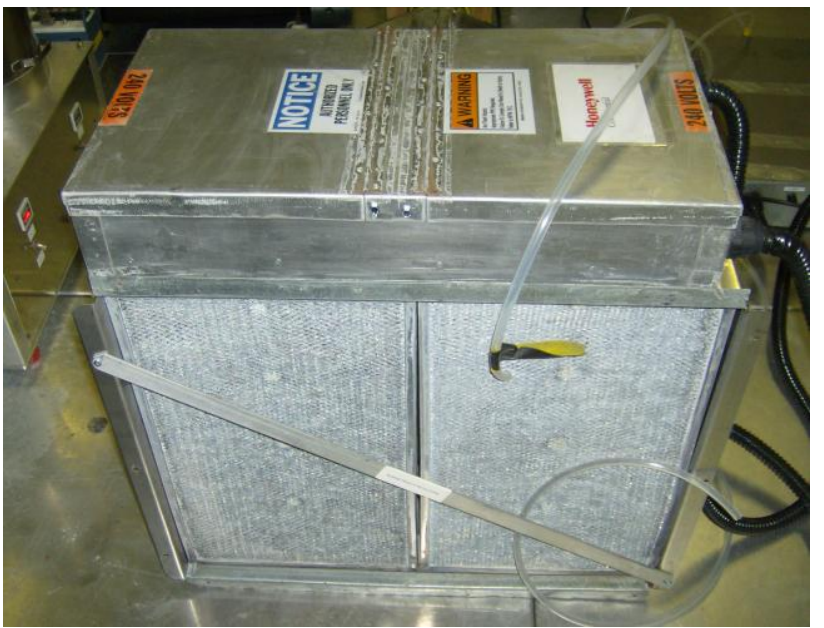

Figure 2. Breadboard PCO test article.

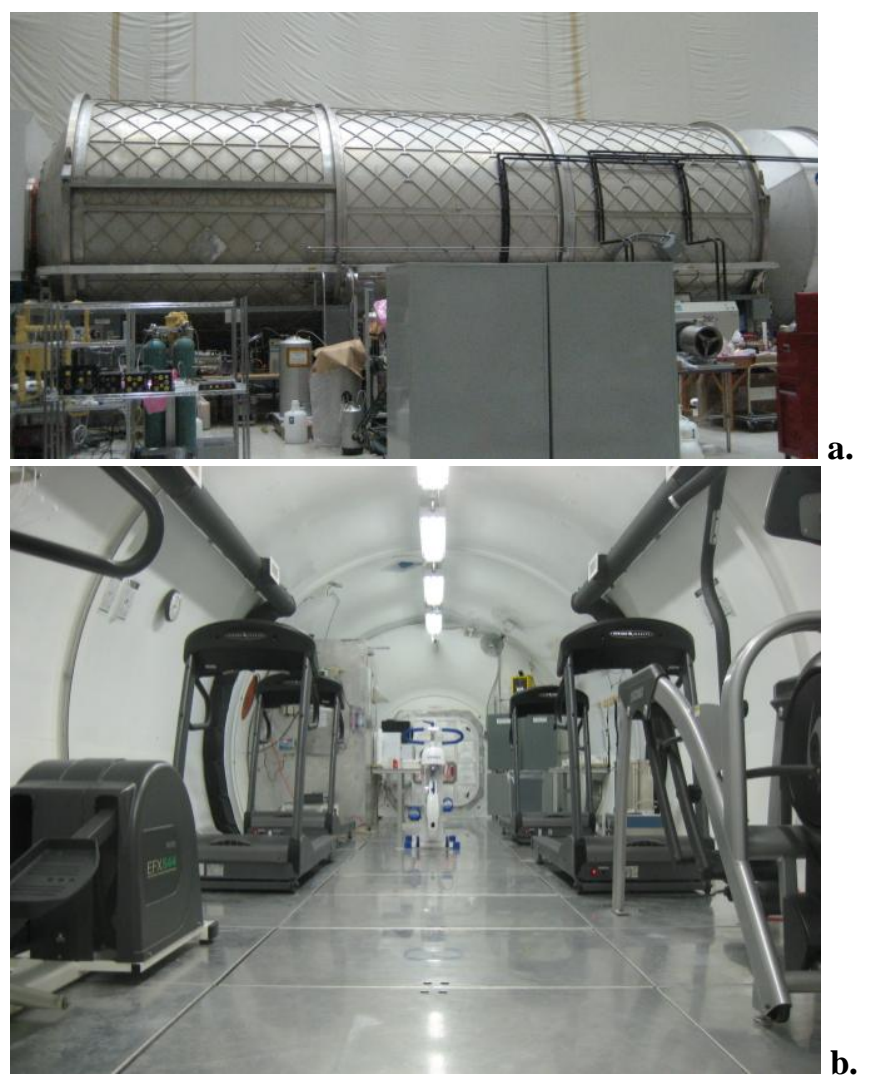

Figure 3. Regenerative ECLS System Module Simulator. a. exterior view, $b$. interior view.

The PCO system was challenged with five mixtures of VOC's as described in Table 1. The compounds used for the challenge mixtures were selected based on their observed incidence in ISS cabin air quality analysis results and their importance for ECLS system TCC and water processing equipment design and performance. ${ }^{4,5}$ Mixture 5 was chosen to include a broader spectrum of contaminants. Target Concentrations at PCO start-up are listed in two units of measure. 
At the beginning of each chemical challenge run, the REMS chamber was closed and conditioned with the desired challenge mixture until the target concentrations listed in Table 1 were reached. Once the desired concentrations were reached, the test rig fan was powered and the PCO unit lamps were turned on. The chemical challenge mixture was injected continuously throughout each test run at the rates listed by Table 1 . The PCO inlet conditions were sampled using the FTIR and GC instruments until a steady-state was reached. At this point, the PCO outlet conditions were sampled to observe the single-pass performance of the PCO.

A total of seven chemical challenge runs were completed. The first five chemical challenge runs were conducted at 84.95 $\mathrm{m}^{3} / \mathrm{hr}\left(50 \mathrm{ft}^{3} /\right.$ minute) flow conditions through the PCO unit using challenge mixtures 1 through 5 . Two additional runs were accomplished at $127.4 \mathrm{~m}^{3} / \mathrm{hr}$ $\left(75 \mathrm{ft}^{3} /\right.$ minute) and 169.9 $\mathrm{m}^{3} / \mathrm{hr} \quad\left(100 \quad \mathrm{ft}^{3} /\right.$ minute $)$ using challenge mixture 1 .

Table 1. PCO testing challenge contaminant mixtures.

\begin{tabular}{|l|c|c|c|c|c|c|c|c|}
\hline \multirow{2}{*}{ Chemical } & \multirow{2}{*}{$\begin{array}{c}\text { Injection } \\
\text { Rate } \\
(\mathbf{m g} / \mathbf{h r})\end{array}$} & \multicolumn{2}{|c|}{$\begin{array}{c}\text { Concentration at } \\
\text { PCO Start-up }\end{array}$} & \multicolumn{5}{c|}{ Challenge Mixture } \\
\hline & $\left(\mathbf{m g} / \mathbf{m}^{\mathbf{3}}\right)$ & $\mathbf{( p p m )}$ & $\mathbf{1}$ & $\mathbf{2}$ & $\mathbf{3}$ & $\mathbf{4}$ & $\mathbf{5}$ \\
\hline \hline Ethanol & 135 & 7.6 & 4.0 & $\checkmark$ & $\checkmark$ & $\checkmark$ & $\checkmark$ & $\checkmark$ \\
\hline m-Xylene & 2.0 & 0.14 & 0.032 & & $\checkmark$ & & & $\checkmark$ \\
\hline Dichloromethane & 1.2 & 0.08 & 0.023 & & & $\checkmark$ & & $\checkmark$ \\
\hline Acetone & 3.5 & 0.52 & 0.22 & & & & $\checkmark$ & $\checkmark$ \\
\hline Acetaldehyde & 3.2 & 0.2 & 0.11 & & & & & $\checkmark$ \\
\hline Methanol & 6.6 & 0.3 & 0.23 & & & & & $\checkmark$ \\
\hline 2-Propanol & 5.1 & 0.3 & 0.12 & & & & & $\checkmark$ \\
\hline Propylene glycol & 38.2 & 1.3 & 0.42 & & & & & $\checkmark$ \\
\hline Benzyl alcohol & 5.1 & 0.03 & 0.007 & & & & & $\checkmark$ \\
\hline
\end{tabular}

\section{Results}

Testing results of Honeywell's PCO unit are detailed below. Because ethanol was the primary contaminant for trials 1-5, bulk ethanol reduction and corresponding acetaldehyde production is addressed first. This is followed by a qualitative comparison of steady state reduction in secondary contaminants for trials 1-5. Finally, data from trial 1 is combined with data from trials 6 and 7 to compare performance at each of three flow rates.

\section{A. PCO Unit Catalyst Development}

Honeywell's catalyst developmental testing indicated both light and dark reactions were possible. For operation at $25{ }^{\circ} \mathrm{C}$, the light reaction provided $>99 \%$ oxidation of ethanol with $>99 \%$ selectivity toward $\mathrm{CO}_{2}$ when challenged with $25.45 \mathrm{mg} /$ minute ethanol ( $\sim 13 \mathrm{ppm}$ ethanol). The dark reaction, when challenged with the same quantity of ethanol, provided $14 \%$ oxidation of ethanol with $\sim 93 \%$ selectivity toward $\mathrm{CO}_{2}$. Honeywell also challenged the catalyst with $\sim 4.5 \mathrm{ppm}$ dichloromethane which showed a concentration decrease of $\sim 1.5 \mathrm{ppm}$ over 20 minutes.

\section{B. Trials 1-5: Bulk Ethanol Reduction and Corresponding Acetaldehyde Production at $84.95 \mathrm{~m}^{3} / \mathrm{hr}$}

For trials 1-5, the PCO unit was challenged with a bulk concentration of ethanol. In each of these trials, acetaldehyde concentration was shown to rise during ethanol reduction. It should be noted that ethanol data was collected by the FTIR, while acetaldehyde data was collected by the GC. For each set of data, the green line indicates the reportable limit of the GC for acetaldehyde. The following summarizes results for each trial.

\section{Trial 1: Mixture 1}

For trial 1, the PCO unit was challenged with ethanol alone. The REMS ethanol concentration was approximately 5 ppm before the PCO unit lamps were powered, as shown in Fig. 4.

Once activated, the PCO successfully lowered the REMS concentration and maintained the circulating concentration to $\sim 0.5 \mathrm{ppm}$. Acetaldehyde in the system was shown to increase during the reduction of ethanol, but returned to initial concentration once the system reached steady state.

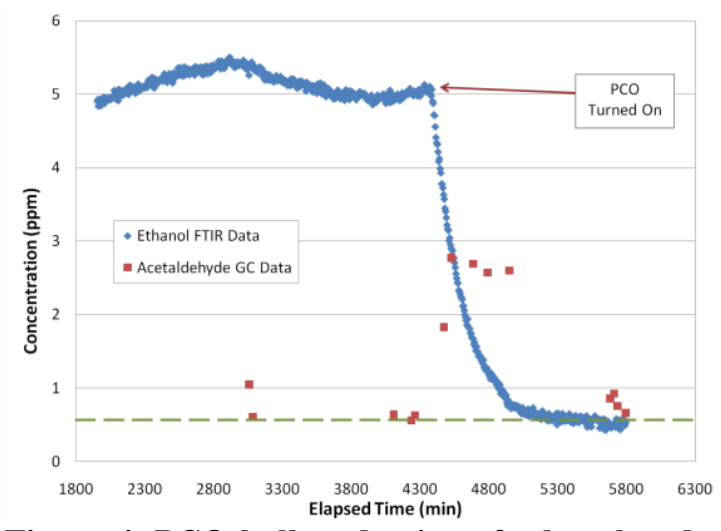

Figure 4. PCO bulk reduction of ethanol and acetaldehyde when challenged with Mixture 1 at $84.95 \mathrm{~m}^{3} / \mathrm{hr}$. Dashed line indicates $G C$ lower reportable limit for acetaldehyde. 


\section{Trial 2: Mixture 3}

In trial 2, the PCO unit was challenged with mixture 3 containing both ethanol and dichloromethane as previously described. In addition to dichloromethane, which will be discussed later, the REMS initially contained $\sim 6.5$ ppm ethanol as shown in Fig. 5. This value is more than $50 \%$ higher than the target of $4.03 \mathrm{ppm}$. Despite this higher initial concentration, the PCO reduced the amount of ethanol to a steady state of $\sim 0.5 \mathrm{ppm}$, the same value observed when reducing from $5 \mathrm{ppm}$ as observed in trial 1. Acetaldehyde concentration was shown to increase during the decrease in ethanol reduction but decreased to low levels at steady state. This indicates incomplete single-pass oxidation of ethanol, but sufficient reaction (upon multiple passes) of acetaldehyde to eventually decrease bulk acetaldehyde concentrations. Note that the break in the data is due to sampling from the exit (port 6) of the PCO for a short time to determine single pass conversions.

\section{Trial 3: Mixture 4}

During trial 3, the PCO unit was challenged with mixture 4 containing both ethanol and acetone as previously described. In addition to acetone, which will be discussed later, the REMS initially contained $\sim 4 \mathrm{ppm}$ ethanol and $\sim 1$ ppm acetaldehyde as seen in Fig. 6. This mixture was very near the $4.03 \mathrm{ppm}$ ethanol target, but much higher than the $0 \mathrm{ppm}$ acetaldehyde target. After activating the PCO unit, there was a steady decrease in ethanol concentration to a minimum value of $\sim 0.5 \mathrm{ppm}$. Acetaldehyde, as observed in previous trials, showed an increase as the bulk of the ethanol was reduced. This increase was followed by a decrease over time indicating acetaldehyde production from ethanol, and a slow reduction over time.

\section{Trial 4: Mixture 5}

During trial 4, the PCO unit was challenged with mixture 5 containing nine different contaminants as previously described. In addition to the other seven contaminants, which will be discussed later, the REMS initially contained $\sim 3.5 \mathrm{ppm}$ ethanol and $\sim 1.0 \mathrm{ppm}$ of acetaldehyde. The initial ethanol concentration was slightly below the target of $4.03 \mathrm{ppm}$ and the acetaldehyde was significantly higher than the $0 \mathrm{ppm}$ target. The change in these contaminants after the PCO unit was initiated is shown in Fig. 7. It is clear from the graph that acetaldehyde concentration increased as ethanol concentration decreased. However, the acetaldehyde concentration returned to initial concentrations when the system reached steady state.

\section{Trial 5: Mixture 2}

During trial 5, the PCO unit was challenged with mixture 2 containing both ethanol and $\mathrm{m}$-xylene as previously described. In addition to m-xylene, which will be discussed later, the REMS initially contained $\sim 4.2 \mathrm{ppm}$ ethanol and $\sim 0.35$ ppm acetaldehyde, as shown in Fig. 8 . The initial concentration of ethanol was very close to the target value. Once the PCO was initiated, ethanol concentration decreased steadily until a steady state concentra-

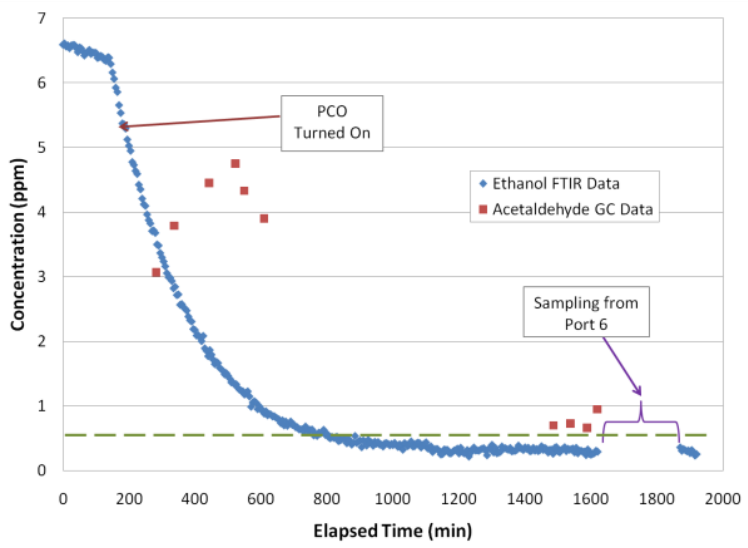

Figure 5. Concentration dynamic of ethanol and acetaldehyde when challenged with mixture 3 at $84.95 \mathrm{~m}^{3} / \mathrm{hr}$. Dashed line indicates $G C$ reportable limit for acetaldehyde.

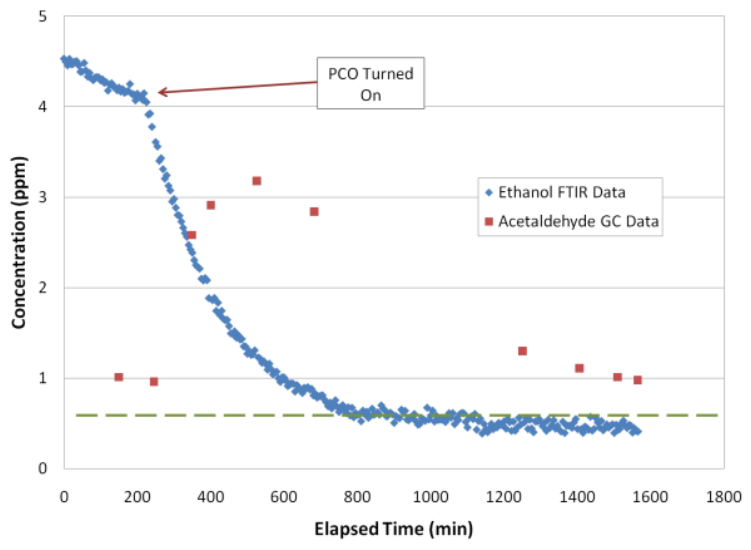

Figure 6. Concentration dynamic of ethanol and acetaldehyde when challenged with mixture 4 at $84.95 \mathrm{~m}^{3} / \mathrm{hr}$. Dashed line indicates GC reportable limit for acetaldehyde.

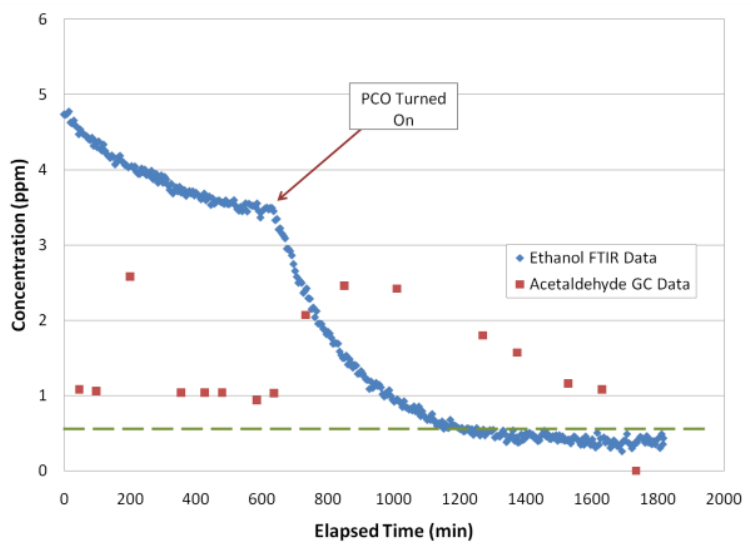

Figure 7. Concentration dynamic of ethanol and acetaldehyde when challenged with mixture 5 at $84.95 \mathrm{~m}^{3} / \mathrm{hr}$. Dashed line indicates GC reportable limit for acetaldehyde. 


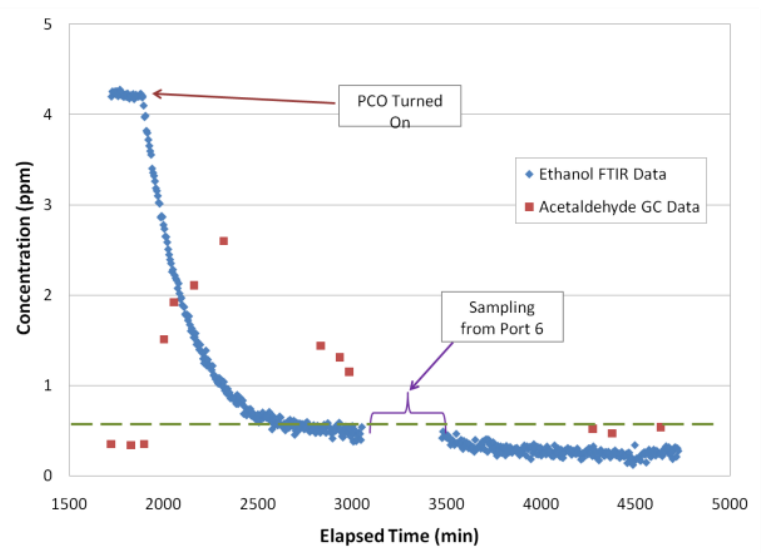

Figure 8. Concentration dynamic of ethanol and acetaldehyde when challenged with mixture 2 at $84.95 \mathrm{~m}^{3} / \mathrm{hr}$. Dashed line indicates GC reportable limit for acetaldehyde.

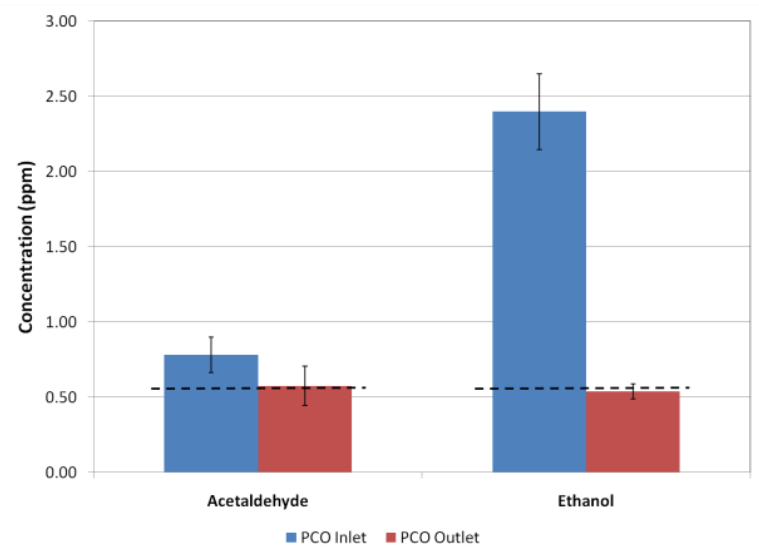

Figure 9. Single pass concentration reduction of PCO when challenged with mixture 1 at $84.95 \mathrm{~m}^{3} / \mathrm{hr}$. Error bars indicate standard deviation, dashed lines indicate the GC reportable limit.

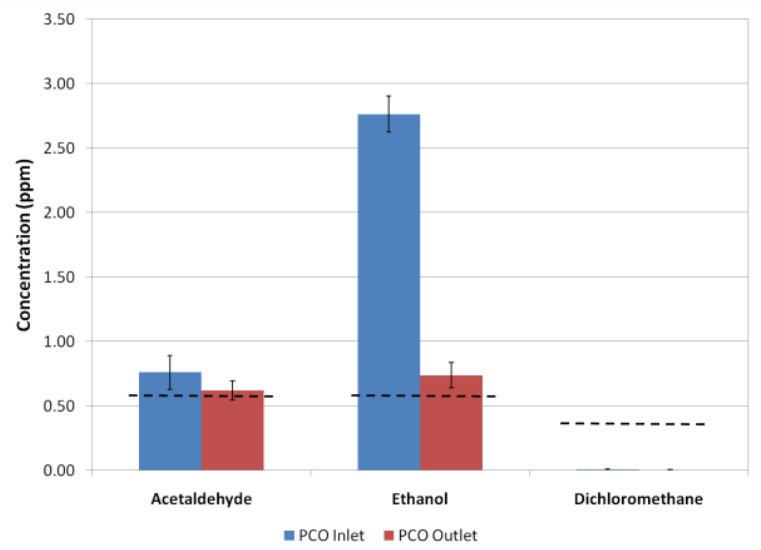

Figure 10. Single pass concentration reduction of PCO when challenged with mixture 3 at $84.95 \mathrm{~m}^{3} / \mathrm{hr}$. Error bars indicate standard deviation, dashed lines indicate the GC reportable limit. tion of $\sim 0.5 \mathrm{ppm}$ was reached. During this time, the acetaldehyde concentration increased significantly. As the ethanol concentration was approached the lower steady state concentration, acetaldehyde ultimately returned to initial values. Note that the break in the data is due to sampling from the exit (port 6) of the PCO for a short time to determine single pass conversion.

\section{Trials 1-5: Steady State Reduction of Contami- nants at $84.95 \mathrm{~m}^{3} / \mathrm{hr}$.}

Following the bulk ethanol concentration reduction for each trial, a steady-state analysis of contaminant removal was conducted. GC reportable limits of each contaminant are detailed in Table 2, and are indicated in each chart by dashed lines. The following summarizes the results for each trial.

1. Trial 1: Steady State Reduction of Mixture 1

Once the concentrations of ethanol and acetaldehyde in the REMS reached steady-state, the inlet and outlet of the PCO were sampled to show single pass removal. A bar graph of average GC data is shown in Fig. 9. Ethanol concentration clearly decreased while acetaldehyde concentration showed no significant change. In a single pass, ethanol concentration decreased by a factor of $\sim 4.5$.

2. Trial 2: Steady State Reduction of Mixture 3

Steady state removal of ethanol, acetaldehyde, and dichloromethane were evaluated in trial 2. Single pass conversion of these contaminants is shown in Fig. 10. Both inlet and outlet values of dichloromethane were below the GC lower reportable limit. However, qualitatively, there was no significant decrease in dichloromethane $(0.007 \pm 0.006 \mathrm{ppm}$ at inlet versus $0.005 \pm 0.001$ ppm at outlet). Similarly, there was no significant decrease in acetaldehyde concentration, although this is not conclusive due to the presumed production of acetaldehyde during ethanol reaction and values at the lower reportable limit of the GC. Despite this apparent lack of

Table 2. GC reportable limits. $G C$ detector responses below these limits are considered to be "trace" concentrations and are used for reference only.

\begin{tabular}{|l|c|}
\hline \multicolumn{1}{|c|}{ Chemical } & $\begin{array}{c}\text { GC Reportable } \\
\text { Limit }(\mathbf{p p m})\end{array}$ \\
\hline \hline Acetaldehyde & 0.555 \\
\hline Methanol & 0.763 \\
\hline Ethanol & 0.531 \\
\hline Acetone & 0.421 \\
\hline Dichloromethane & 0.288 \\
\hline Propanol & 0.407 \\
\hline Propylene glycol & 0.321 \\
\hline m-Xylene & 0.230 \\
\hline Benzyl alcohol & 0.226 \\
\hline
\end{tabular}


change between the inlet and outlet, bulk concentration reduction results, shown previously by Fig. 5 indicates removal of both ethanol and acetaldehyde does occur within the PCO unit. Ethanol concentration decreased by nearly a factor of 4 .

\section{Trial 3: Steady State Reduction of Mixture 4}

Steady state reduction of ethanol, acetaldehyde, and acetone were evaluated in trial 3. A comparison of the inlet and outlet of the PCO, once the system had reached a steady state, is shown in Fig. 11. The graphs indicate no significant decrease in any of the contaminants in a single pass through the PCO. However, this may be attributed to poor data, as it is clear from Fig. 6, that both ethanol and acetaldehyde were reduced during operation of the PCO unit. Additionally, measured levels of acetone were well below the GC lower reportable limit.

\section{Trial 4: Steady State Reduction of Mixture 5}

Steady state reduction of ethanol, acetaldehyde, methanol, m-xylene, dichloromethane, acetone, methanol, 2-propanol, propylene glycol, and benzyl alcohol were evaluated in trial 4. Table 3 shows the measured initial concentrations in the REMS compared to the target concentrations of each contaminant. The GC lower re-

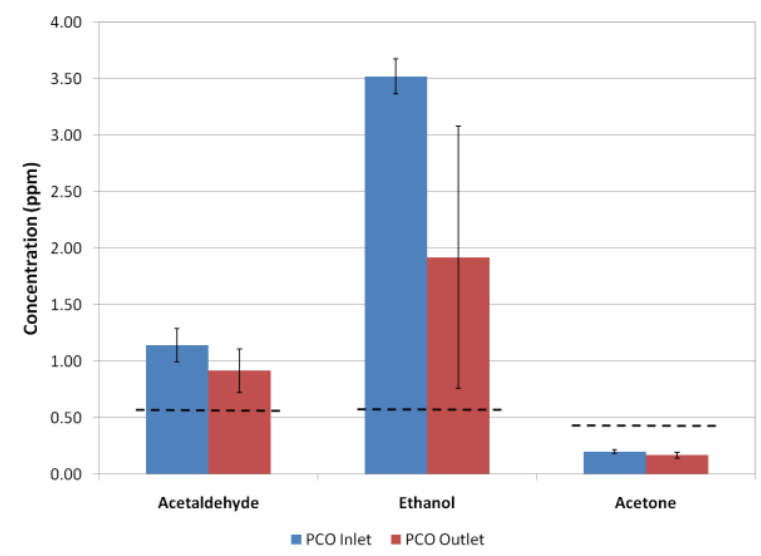

Figure 11. Single pass concentration reduction of PCO when challenged with mixture 4 at $84.95 \mathrm{~m}^{3} / \mathrm{hr}$. Error bars indicate standard deviation, dashed lines indicate the GC reportable limit. portable limits are listed for comparison. Based on reported GC values, all of the contaminants were initially high with the exceptions of ethanol, m-xylene, and propylene glycol. Ethanol was only slightly below the target. The concentration of m-xylene was about $33 \%$ lower than targeted while propylene glycol was only about $2 \%$ of the desired concentration. The remaining contaminants ranged from being $10 \%$ over target (2-propanol) to being an order of magnitude higher than the target (acetaldehyde).

With the exception of ethanol, m-xylene, acetaldehyde and propylene glycol, there was no significant decrease observed in the concentration of the contaminants in the REMS between pre-PCO GC values and values observed

Table 3. Mixture 5 measured vs. target concentrations.

\begin{tabular}{|l|c|c|c|}
\hline \multirow{2}{*}{ Chemical } & \multicolumn{3}{c|}{ Concentration (ppm) } \\
\cline { 2 - 4 } & Target & Measured & $\begin{array}{c}\text { GC } \\
\text { Reportable } \\
\text { Limit }\end{array}$ \\
\hline \hline Ethanol & 4 & 3.5 & 0.53 \\
\hline m-Xylene & 0.032 & 0.02 & 0.23 \\
\hline Dichloromethane & 0.023 & 0.05 & 0.29 \\
\hline Acetone & 0.22 & 0.34 & 0.42 \\
\hline Acetaldehyde & 0.11 & 1.04 & 0.56 \\
\hline Methanol & 0.23 & 0.55 & 0.76 \\
\hline 2-Propanol & 0.12 & 0.11 & 0.41 \\
\hline Propylene glycol & 0.42 & 0.01 & 0.32 \\
\hline Benzyl alcohol & 0.007 & 0.01 & 0.23 \\
\hline
\end{tabular}
when the REMS reached steady state $(1,500-$ 1,800 minutes).

A steady-state comparison of PCO inlet and outlet ports is shown in Fig. 12. Due to the low concentrations of certain contaminants, Fig. 13 provides a scaled version of the lowconcentration contaminants. With the exception of propylene glycol and benzyl alcohol, all contaminants showed a decrease in concentration during a single pass reduction in the PCO. The results for propylene glycol, benzyl alcohol, and 2-propanol were in conclusive due to the error in measurements. Dichloromethane and ethanol concentration at the PCO outlet decreased by the most relative to the PCO inlet at $75 \%$ and $83 \%$, respectively. Concentrations of acetaldehyde, methanol, acetone, and xylene at the PCO outlet decreased at the more moderate percen-

tages of $45 \%, 29 \%, 27 \%$, and $37.5 \%$, respectively, relative to the PCO inlet concentration.

\section{Trial 5: Steady State Reduction of Mixture 2}

Steady state reduction of ethanol, acetaldehyde, and m-xylene was evaluated in trial 4. Figure 14 shows the results of single pass conversion as observed by the GC. Ethanol concentration was shown to decrease by nearly a factor of four $-3.75 \mathrm{ppm}$ to $1.04 \mathrm{ppm}$. Acetaldehyde and xylene were shown to decrease by approximately half$1.3 \mathrm{ppm}$ to $0.76 \mathrm{ppm}$ and $0.0076 \mathrm{ppm}$ to $0.0035 \mathrm{ppm}$, respectively - although detected m-xylene values are well below the GC lower reportable limit. 


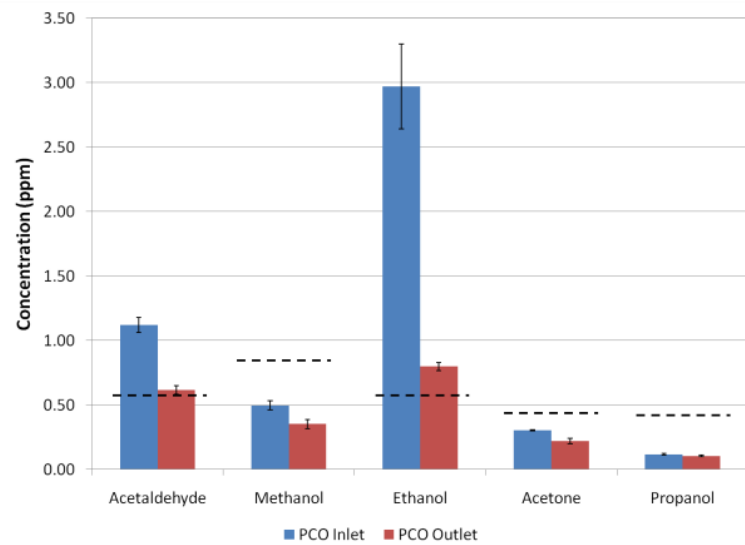

Figure 12. Single pass concentration reduction of PCO when challenged with mixture 5 at $84.95 \mathrm{~m}^{3} / \mathrm{hr}$. Error bars indicate standard deviation, dashed lines indicate GC reportable limit.

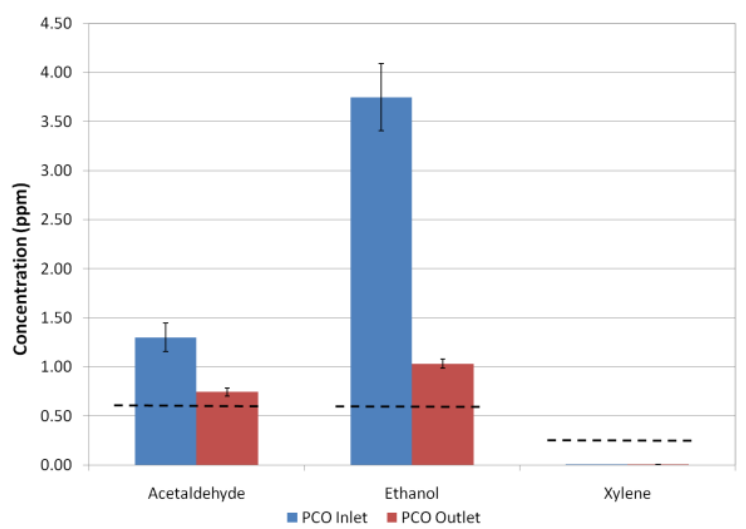

Figure 14. Single pass concentration reduction of PCO when challenged with mixture 2 at $84.95 \mathbf{~ m}^{3} / \mathrm{hr}$. Error bars indicate standard deviation, dashed lines indicate GC reportable limit.

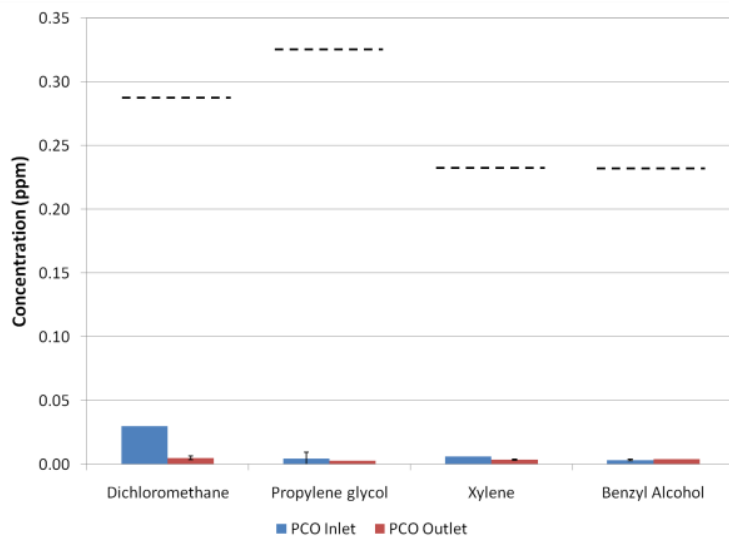

Figure 13. Low concentration contaminants during the single pass reduction of $\mathrm{PCO}$ when challenged with mixture 5. Error bars indicate standard deviation, dashed lines indicate GC reportable limit.

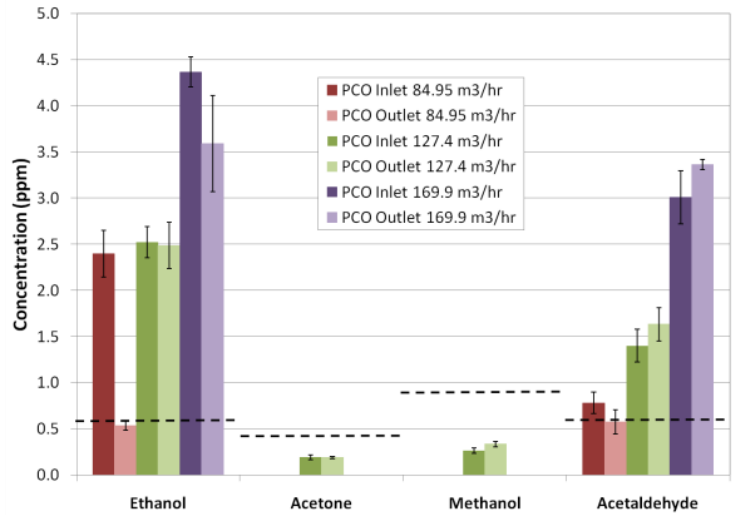

Figure 15. PCO reduction of Mixture 1 at $84.95 \mathrm{~m}^{3} / \mathrm{hr}, 127.4 \mathrm{~m}^{3} / \mathrm{hr}$ and $169.9 \mathrm{~m}^{3} / \mathrm{hr}$ flow rates. Error bars indicate standard deviation, dashed lines indicate GC reportable limit.

\section{Trials 1, 6 and 7: Influence of Flow Rate on PCO Performance}

During trials 1,6 , and 7, the PCO unit was challenged with mixture 1 at flow rates of $84.95 \mathrm{~m}^{3} /$ hour, 127.43 $\mathrm{m}^{3} /$ hour, and $169.9 \mathrm{~m}^{3} /$ hour, respectively. While every attempt was made to have similar initial conditions for each test, this was not always feasible as seen in Fig. 15. For flow rates of $84.95 \mathrm{~m}^{3} /$ hour and $127.43 \mathrm{~m}^{3} /$ hour, the inlet ethanol concentration was $\sim 2.5 \mathrm{ppm}$, while the concentration for the $169.9 \mathrm{~m}^{3} /$ hour flow rate was $\sim 4.25 \mathrm{ppm}$. Similarly, the inlet acetaldehyde concentration for flow rates $84.95 \mathrm{~m}^{3} /$ hour and $127.43 \mathrm{~m}^{3} /$ hour were $\sim 1.35 \mathrm{ppm}$, while the concentration for the $169.9 \mathrm{~m}^{3} /$ hour flow rate was $\sim 2.8 \mathrm{ppm}$. Inexplicably, acetone and methanol were observed during the $127.43 \mathrm{~m}^{3} /$ hour trail, although values were below the GC reportable limit. These contaminants were not observed in the $84.95 \mathrm{~m}^{3} /$ hour or $169.9 \mathrm{~m}^{3} /$ hour trials.

Significant ethanol concentration reduction was observed for the $84.95 \mathrm{~m}^{3} /$ hour flow rate only. Increased flow rates showed no significant concentration reduction for ethanol or acetaldehyde. It should be noted that the unit was only designed for $76.46 \mathrm{~m}^{3} /$ hour ( $45 \mathrm{ft}^{3} /$ minute) flow. Additionally, if no concentration reduction was occurring at the higher flows, the continuous injection of ethanol into the system should have increased total REMS ethanol concentration over time. However, this was not observed. Thus, based on the GC data, the PCO unit, while not reducing the total ethanol concentration in the REMS chamber, appeared to be capable of removing ethanol at the rate of introduction into the REMS chamber. 


\section{Discussion}

A breadboard PCO unit was tested in a total of seven trials. Trials 1-5 were conducted to evaluate PCO unit performance when challenged with five contaminant mixtures at $84.95 \mathrm{~m}^{3} /$ hour. Trials 6 and 7 were conducted to determine the effect of flow rate on PCO performance.

In general, testing results are assessed based on limited GC data. All GC sampling was accomplished manually resulting in fewer data points than desired for each trial. Secondly, in all but the first trial, the bulk concentration in the REMS working volume was not entirely stable before the PCO was activated. While the data were accepted as if the bulk concentration had been constant, more conclusive results will require additional time for the REMS to stabilize before PCO unit activation. Thirdly, there were some observed discrepancies between FTIR and GC readings for ethanol - the only chemical targeted with both instruments. These analytical methods should be consistent with both themselves and each other to lend reliability to each method. Occasionally, there was an observed variation in GC sample data when samples were taken within minutes of each other. This variation was found to result from differing performance of the two GC preconcentration traps.

With the exception of ethanol and acetaldehyde, all measured contaminant levels were below GC lower reportable limits, making the results more qualitative than quantitative. For future testing, it will be necessary to either calibrate the $\mathrm{GC}$ at concentrations similar to those being tested, or complete analyses with a another method capable of measuring the low ppm levels of contaminants.

Completion of trials 1-5 provided data on each of the five contaminant mixtures. Each contained ethanol targeted to $4.03 \mathrm{ppm}$. Although each of the trials started with a different level of ethanol, when the data are time-corrected and overlaid, as seen in Fig. 16, it is clear that the ethanol concentration reduction rate was nearly identical regardless of the mixture. This indicates that secondary or mixtures of contaminants did not affect the ethanol concentration reduction rate.

Additionally, acetaldehyde was produced during the concentration reduction of the mixtures as shown in Fig. 17. The acetaldehyde concentration would dramatically increase during the initial concentration reduction of ethanol. The acetaldehyde concentration would peak near the end of the bulk ethanol concentration reduction and would level out to values similar to initial concentrations. Muggli et al reported a similar effect when using photocatalytic oxidation for ethanol reduction. ${ }^{6}$ Although Honeywell did not report acetaldehyde production when the PCO catalyst was illuminated; there was an observed dark reaction. The expectation for the breadboard PCO unit was no acetaldehyde production. Acetaldehyde production by the breadboard PCO unit may be explained in three possi-

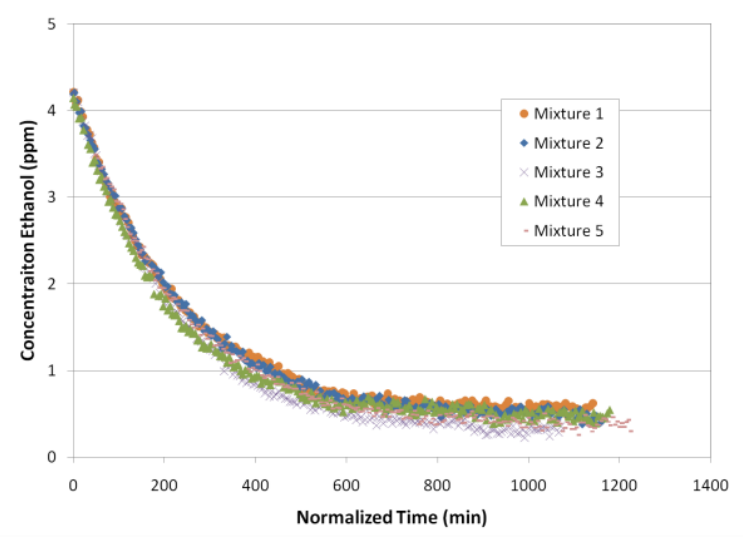

Figure 16. Ethanol concentration reduction for all mixtures at $84.95 \mathrm{~m}^{3} / \mathrm{hr}$.

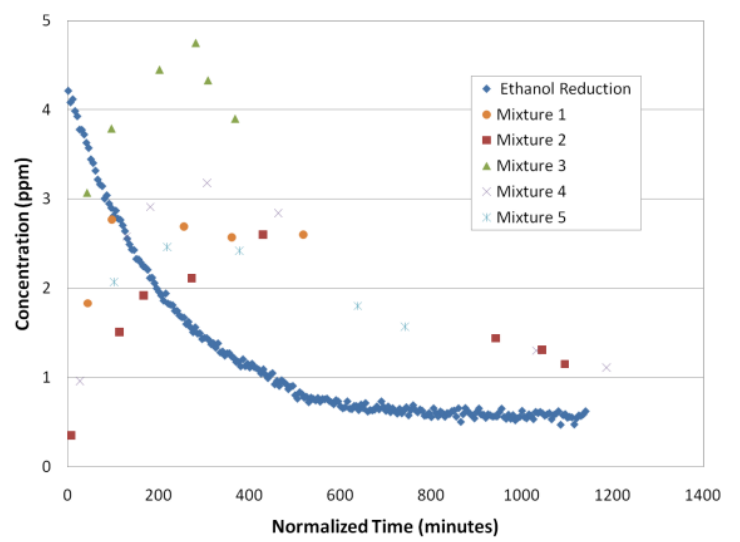

Figure 17. Acetaldehyde concentration rises as ethanol concentration falls for all mixtures.

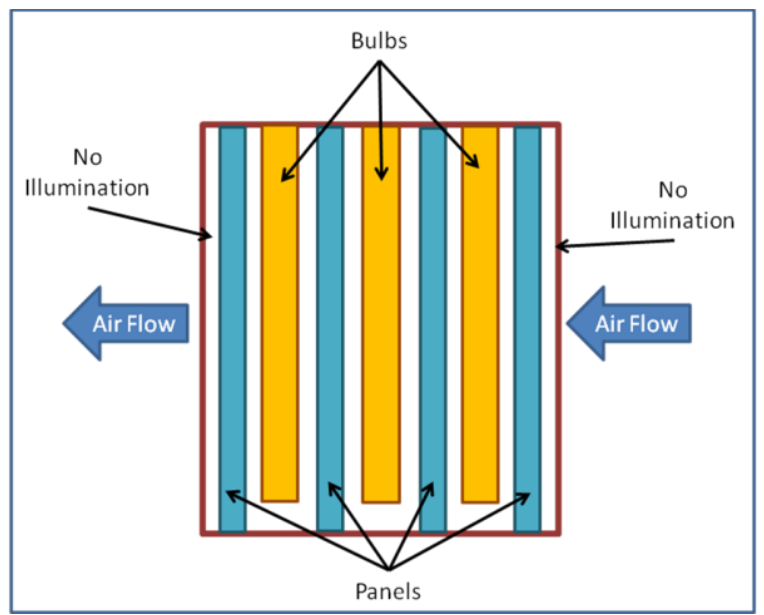

Figure 18. PCO unit design prevents catalyst illumination at the entrance and exit of the unit. 
ble ways. First, Honeywell was testing catalyst coated on a different substrate geometry than the final mesh panel geometry. The difference in catalyst substrate geometry of the systems would be expected to introduce some discrepancies. Second, Honeywell reported that when the lamps were off, a dark reaction was observed in which high concentrations of acetaldehyde were produced from ethanol. Due to the design of the breadboard PCO unit, the outer panels each had a side that was not illuminated as shown in Fig. 18. These "dark" areas may have contributed to the observed levels of acetaldehyde. Third, during pre-conditioning of the REMS, the PCO was exposed to bulk air. While there was no forced flow across the system, it is possible that ethanol diffused through the air to pre-adsorb on the PCO screens. The exposure of the system to ethanol while "dark" would have produced acetaldehyde. Because there was no flow through the system, the only available acetaldehyde transport would have been through diffusion. The bulk of the acetaldehyde would have been concentrated near the PCO unit. When the system was activated, this bulk concentration of acetaldehyde would then be introduced to the REMS where it was detected. Muggli's paper also indicated the formation of acetic acid. Testing at MSFC did not evaluate samples for this compound with the GC or FTIR. However, test engineers commented on a "vinegar-like" odor in the REMS during testing. Based on this reported odor, it is highly likely that the PCO also generated acetic acid. The formation of acetaldehyde and acetic acid then become a concern to cabin air quality as well as downstream water processing equipment which is sensitive to acetate concentration in feed water.

As stated previously, trials 6 and 7 were completed to compare ethanol concentration reduction by the PCO at higher flow rates than that tested in trial 1. This comparison, shown in Fig. 19, clearly shows a decrease in efficiency with increasing flow rate. Not only was the rate of concentration reduction decreased for increased flow rates, as indicated by the slope of the lines, but also the ultimate steady-state concentration was higher with increased flow rate. Thus, even with recycling of the streams, the unit could not lower the concentrations beyond a flow rate-based threshold. Because the breadboard PCO unit was designed for $76.46 \mathrm{~m}^{3} /$ hour flow rates, it was expected that the rate of concentration reduction would decrease due to lower residence times in the reactor. However, it was somewhat surprising to see that the concentration plateau decreased. This suggests that mass transport of ethanol

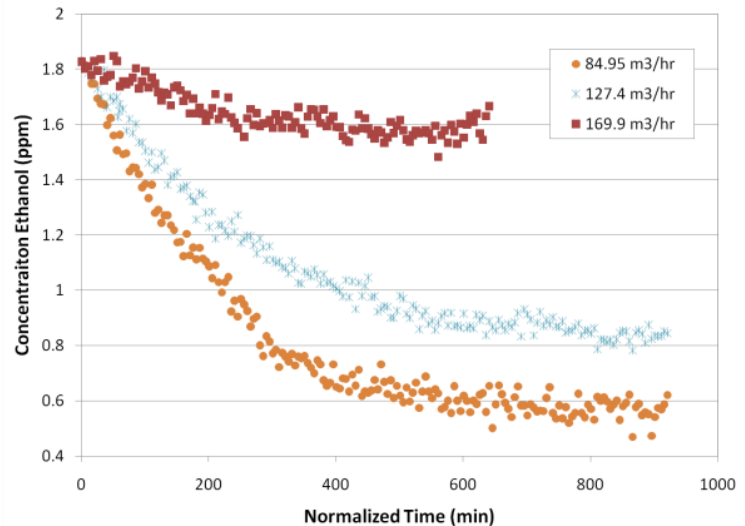

Figure 19. PCO efficiency based on flow rate when challenged with mixture 1.

molecules from the bulk flow to the surface of the catalyst is the rate limiting step rather than the catalytic activity of the surface.

MSFC's testing of Honeywell's PCO unit used simplified mixtures designed to represent larger groups of VOC's (acetone for ketones, dichloromethane for halocarbons, etc.). Testing completed by Hodgson et al explored more complex mixtures challenging a PCO unit containing a tungsten oxide catalyst with individual VOC concentrations below $10 \mathrm{ppb}^{7}$ The group reported that alcohols and glycol ethers were the most reactive chemical classes and were reduced by about $70 \%$ in testing. While the breadboard PCO unit was not challenged with glycol ethers, Hodgson's observed ethanol concentration trend was also observed in MSFC's testing during which observed ethanol single pass efficiency was around $72-75 \%$ for most mixtures. Muggli reports that ketones and hydrocarbons were less reactive. This was also observed in MSFC's testing of the breadboard PCO unit.

Testing of Honeywell's PCO unit was completed to explore the potential of using photocatalytic oxidation as a replacement to SOA TCC systems. From the data gathered in this study, two things are very clear. First, a PCO unit would not be a complete replacement for the existing TCC system. Due to the formation of unwanted byproducts, namely acetaldehyde and potentially acetic acid, as well as the limited activity for 2-propanol reaction and probable inactivity for benzyl alcohol and propylene glycol reaction, it is clear that the PCO alone does not have the necessary capability to handle all the contaminants that may be present in space cabins. Second, there is significant concern with siloxanes. For this testing, the unit was not challenged with siloxanes due to a paper published by Hay et al in which siloxanes were shown to deactivate photocatalytic air purifiers by coating the catalyst with a silicon-rich layer. ${ }^{8}$ This effect, coupled with the first concern for the PCO unit, means that the PCO unit, if used as an alternative to SOA TCC technology would require additional, supportive equipment to operate. The system would require upstream removal of siloxanes as well as a supplemental processing stages for contaminants that PCO is not capable of mineralizing. Thus, the PCO could not be used as a complete replacement for SOA TCC technology that uses physical adsorption and thermal catalytic oxidation. 


\section{Summary}

A total of seven trials were completed to explore the performance of a breadboard PCO unit. A summary of the most significant observations is the following:

- Ethanol single pass removal efficiency averaged $74 \%$ for the test trials.

- The ethanol concentration reduction rate, based on bulk REMS concentration, was identical for all tests trials.

- Ethanol single pass removal efficiency is a function of flow rate through the system which is likely due to mass transport limitations.

- The PCO showed capability of removing ethanol, acetaldehyde, m-xylene, acetone, and dichloromethane in at least one test.

- The PCO showed no significant capability for removing 2-propanol, propylene glycol, or benzyl alcohol; however, this may be due to operating at challenge concentrations near analytical method reportable limits.

- Acetaldehyde concentration increased as ethanol concentration decreased for all test trails.

- The observed quantity of acetaldehyde formed is directly proportional to the initial concentration of ethanol in the bulk air.

\section{Conclusions}

Testing of a breadboard PCO unit provided a better understanding of full scale potential. It is clear from the data that a PCO unit may not be a singular answer to future spacecraft TCC technology applications. Rather, the PCO has the capability to reduce large quantities of VOCs but will likely require the assistance of additional processors. In particular, siloxanes must be removed upstream of a PCO system to prevent fouling. The breadboard PCO unit performed similarly to existing hardware as published in scientific journals. Formation of acetaldehyde, and possibly acetic acid, are a cabin air quality concern that must be addressed as PCO process technology development progresses. Finally, additional testing will be crucial to understanding the full capabilities of PCO as a spacecraft cabin TCC technology.

\section{Acknowledgements}

This work was sponsored by the NASA Innovative Partnership Program.

\section{References}

${ }^{1}$ Perry, J., "Trace Chemical Contaminant Generation Rates for Spacecraft Contamination Control System Design," NASA TM-108497, 1995.

2“'Spacecraft Maximum Allowable Concentrations for Airborne Contaminants,” JSC-20584, November 2008.

${ }^{3}$ Perry, J., "The Interaction of Spacecraft Cabin Atmospheric Quality and Water Processing System Performance," 2002-012300, SAE, $32^{\text {nd }}$ International Conference on Environmental Systems, San Antonio, Texas, 2002.

${ }^{4}$ Carter, D. L., Tabb, D., and Perry, J., "Evaluation of an Exploration Water Recovery System Architecture," 2008-01-2140, SAE, $38^{\text {th }}$ International Conference on Environmental Systems, San Francisco, California, 2008.

${ }^{5}$ Perry, J. L., “A Design Basis for Spacecraft Cabin Trace Contaminant Control” 2009-01-2592, SAE, $39^{\text {th }}$ International Conference on Environmental Systems, Savannah, Georgia, 2009.

${ }^{6}$ Muggli, D. S., McCue, J. T., and Falconer, J. L., "Mechanism of the Photocatalytic Oxidation of Ethanol on TiO ${ }_{2}$," Journal of Catalysis, 173, 1998, pp. 470-483.

${ }^{7}$ Hodgson, A. T., Sullivan, D. P., and Fisk, W. J., "Evaluation of Ultra-Violet Photocatalytic Oxidation (UVPCO) for Indoor Air Applications: Conversion of Volatile Organic Compounds at Low Part-per-Billion Concentrations," LBNL-58936, Lawrence Berkeley National Laboratory, California, 2005.

${ }^{8}$ Hay, S. O., Obee, T. N., and Thibaud-Erkey, C., "The Deactivation of Photocatalytic Based Air Purifiers by Ambient Siloxanes," Applied Catalysis B: Environmental; 99, 2010, pp. 435-441. 